\title{
Prey life history influences the evolution of egg mass and reproductive investment in a group of insect predators
}

\author{
Jean-Louis Hemptinne ${ }^{1}$, Emilie Lecompte ${ }^{2}$, Arnaud Sentis ${ }^{3}$, Anthony Dixon ${ }^{4}$, and \\ Alexandra Magro ${ }^{1}$ \\ ${ }^{1}$ Université Fédérale Toulouse Midi-Pyrénées \\ ${ }^{2}$ Université Toulouse III Paul Sabatier \\ ${ }^{3}$ INRAE \\ ${ }^{4} \mathrm{UEA}$
}

April 21, 2021

\begin{abstract}
1. The balance between risk and benefit of exploiting resources drives life history evolution. Predators are naturally recognized as major drivers of the life history evolution of their prey. The concept of an evolutionary arms race posits that prey also influence the life history evolution of their predators. There is far more evidence on the role of predators than of prey. 2 . The goal of this study was to investigate the role of prey in life history evolution of predators using ladybird beetle predators either of aphids or coccids. These particular organisms were chosen because literature shows that the pace of life of aphids is faster than that of coccids and this difference is reflected in the life histories of the ladybirds that specialize on feeding on aphids or coccids. 3. Thirty-four species of ladybird predators of aphids and eight of coccids belonging to five different tribes were collected and reared in the laboratory. The females were weighed as well as their eggs, and their reproductive investment calculated as the number of ovarioles multiplied by the average mass of an egg. Phylogenetic relatedness was controlled for in the statistical analyses. 4. Controlling for female mass revealed that ladybird predators of aphids lay bigger eggs and have a higher reproductive investment than ladybird predators of coccids. These differences are not influenced by phylogenetic relatedness but only by the type of prey. We suggest that ladybird predators of coccids lay smaller eggs because neonate larvae do not have to search, catch and subdue prey, and that they have a smaller reproductive investment because they need to allocate more resources to locate prey. 5. Recognizing the influence of prey on the life history evolution of predators is important for understanding food web dynamics.
\end{abstract}



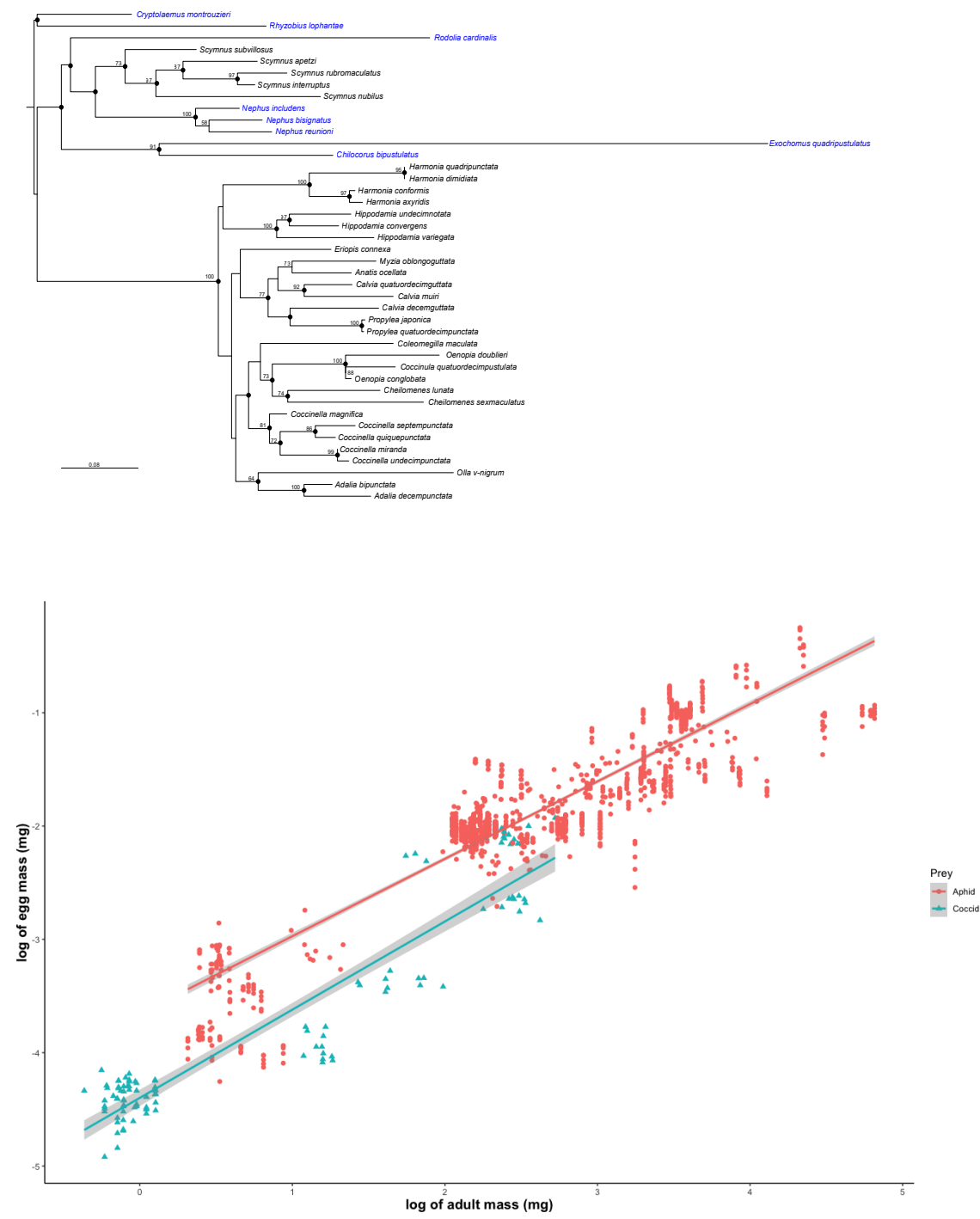

2 


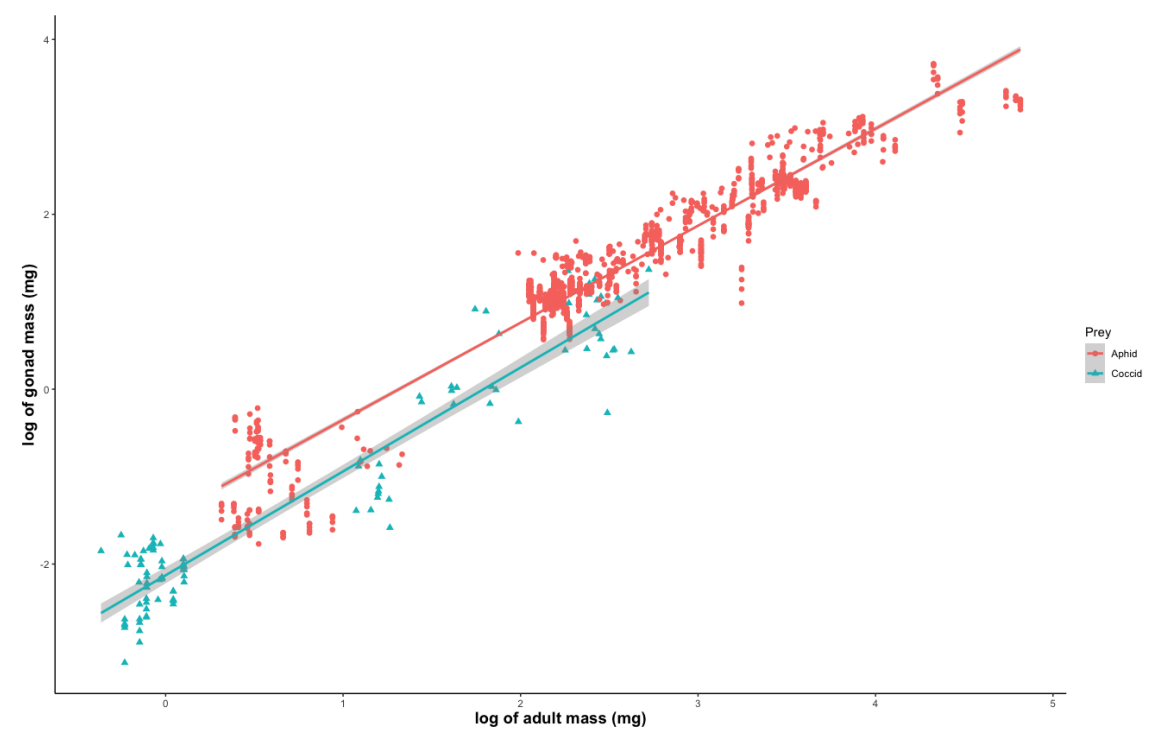

